\title{
EDUCAÇÃO, SAÚDE, SERVIÇO SOCIAL E HUMANIZAÇÃO: DESAFIOS ÉTICOS E PROPOSTAS INSTITUCIONAIS EMANCIPATÓRIAS
}

\author{
César Nunes ${ }^{l}$ \\ "Educar consiste em inventar e reinventar constantemente a \\ civilização humana sem barbárie!" \\ Florestan Fernandes
}

\section{RESUMO}

$\mathrm{O}$ artigo busca caracterizar sobre as matrizes políticas e culturais de nossa prática social, com enfoque para as identidades produzidas pela tradição colonial, sobreposta pela experiência política do império brasileiro, ambas estruturadas a partir da hegemonia das relações escravocratas e patriarcais, consagradas pela onipotência do Estado e suas influências na realidade política. A República e suas fases ou etapas não altera essa identidade até a eclosão de um novo sujeito social, reconhecido nas lutas e movimentos sociais que conquistaram a redemocratização do país após a ditadura militar (19641985) consignando um novo marco histórico, jurídico e social que se materializa nas novas grades de leis e direitos sociais: o estatuto da Criança e do Adolescente, o SUS, as instituições de proteção e direitos da Mulher, as lutas pela igualdade étnica e cultural, as iniciativas de políticas públicas de inclusão e reparação social, as perspectivas de um novo "ethos" ambiental do Brasil, o reconhecimento social tutelar da condição do idoso, dos portadores de necessidades especiais, dos índios, do negro, dos homossexuais, entre outros segmentos e vanguardas civis emancipatórias. Apresenta as tendências históricas e os constituintes éticos e políticos dessa tradição de dominação e aponta possibilidades de inversão, superação e desarticulação dessas tendências ou matrizes autoritárias, a partir da prática política, da ressignificação da formação ética e educacional, da reconstituição dos valores sociais numa prospectiva de solidariedade, humanização, justiça social e democratização política.

PALAVRAS-CHAVES: Humanização; Educação; Emancipação; Ética; Serviço Social.

\footnotetext{
${ }^{1} \mathrm{O}$ autor é professor livre-docente da Faculdade de Educação da UNICAMP, Coordenador do Grupo de Estudos e Pesquisas PAIDEIA e autor de livros e artigos, exerce a chefia do Departamento de Filosofia e História da Educação. E-mail: cnunes@ unicamp.br
} 
A Educação é a mais destacada das dimensões sociais. Educar, em última instância, consiste em produzir o homem para a vida em sociedade. Educar é hominizarse, fazer-se homem, fazer-se pessoa. Mas, ao mesmo tempo, educar é projetar as características humanas no mundo, na realidade natural e na civilização constituída pela marcha histórica de toda a comunidade humana. Assim, educar significa manejar um duplo processo: hominizar-se, isto é, fazer-se homem e humanizar, isto é, fazer o mundo à medida do homem! Esta é a tarefa da educação no tempo em que vivemos. A sociedade da informação, tal como é chamada a nossa época, ou ainda a sociedade do conhecimento, em outras denominações, quer ainda a era tecnológica, em alusões performáticas, despida de critérios éticos e políticos, transforma tudo numa fria corrida competivista, bárbara e cínica. Somos constituídos para a felicidade! Aristóteles, esse mestre da vida prática, já afirmava isso na Antiguidade. Assim, a escola e a educação, em cada uma de suas peculiaridades, necessitam buscar parâmetros éticos, estéticos e pedagógicos humanistas e humanizadores. Educadores e cidadãos, pais e professores haverão de encontrar as grandes matrizes filosóficas, a reger nossa caminhada para um futuro justo, fraterno e democrático, onde haveremos de aprender a viver juntos!

Por força do ofício sempre tenho buscado entender as contradições de nosso tempo e sociedade a partir de seus dados de bastidores, os condicionantes históricos e suas inspirações ideológicas. Não se trata de uma busca arqueológica meramente heurística, ou ainda que se configure como um caprichoso exercício de genealogia conceitual, tão a gosto de tantas epistemologias correntes, fragmentárias e indolores. Mas, ao contrário, tal intento nasce da constatação da angustiante premissa de que não encontramos outra possibilidade de compreender as contradições de nossa realidade se não buscarmos seus marcos históricos e políticos, nem tampouco reuniremos condições 
de superação dessas matrizes se não soubermos a solidez de seus fundamentos. O pensamento mágico, por sua vez, contenta-se com descrições fabulosas, alimenta-se de proposições ahistóricas e quase sempre acaba reforçando as eficientes armadilhas reais da dominação vigente, em não poucas vezes acaba legitimando a liturgia do corpus institucional do establishment e promovendo a continuidade do inusitado cinismo do status quo. É preciso pensar por outros caminhos, corajosos, audazes e viáveis.

Esse mesmo nosso tempo é marcado por rápidas e intensas mudanças. O conhecimento técnico altera radicalmente nossa vida cotidiana interferindo em todas as dimensões de nossa sociedade. A produção material das coisas já não é mais um problema, outros problemas maiores se apresentam aos nossos olhos e nossas mãos. Torna-se necessário criar diretrizes éticas e coordenadas políticas para submeter as conquistas tecnológicas ao interesse e promoção do bem estar de todos. A escola se vê questionada a assumir novas funções e a recuperar alguns de seus atributos clássicos bem como assumir novas identidades. Assim, torna-se necessário hoje planejar uma escola e uma nova proposta de educação voltada para a formação plena da cidadania e para a incorporação da cultura como processo de hominização e de humanização. O conhecimento historicamente acumulado deve ser repassado a cada geração, de maneira sistematizada e criativa, a produzir condições de compreensão da vida, das sociedades e conquistas da civilização humana. Um conhecimento posto a serviço da vida, da felicidade, da justiça e da sustentabilidade de todas as formas de produção e trabalho. A escola de hoje tem que incorporar criativamente os recursos e paradigmas clássicos postos pela tradição e ser capaz de assimilar e ordenar novas relações culturais, novos contextos e disposições. O currículo que almejamos dever articular conhecimento e cultura, a tradição e a contemporaneidade. A finalidade de todo conhecimento e cultura consiste em prover a construção de subjetividades autônomas, criativas e abertas à 
identidade e respeito para com a natureza, à prática da nova estética da convivência, à preservação e cultivo de hábitos elevados, que garantam as diferenças e pluralidades postas pela própria diversidade da vida.

A identidade da escola no Brasil sempre esteve vinculada à finalidade política de dominação. O Estado é seu demiurgo, com suas marcas culturais e práticas excludentes. Estamos muito distantes de termos conquistado os fundamentos da educação pública, leiga, universal, obrigatória e gratuita, propostos pela ideologia burguesa emergente na França Republicana. Muitas coisas nos foram tiradas pela marcha dos interesses hegemônicos em nossa tradição cultural. A educação e a escola ainda padecem de estigmas e disposições arcaicas e anacrônicas.

Hoje assistimos a uma mudança estrutural da identidade do Estado, a partir dos deslocamentos de interesse e ressignificações institucionais determinados pelo rearranjo neoliberal. Trata-se de um momento a exigir de nós um esclarecido tirocínio entre o que é essencialmente novo ou inovador e o que é deserção, medo, capitulação ou expropriação. Esse movimento implica em reconhecer aquelas disposições e elementos que necessariamente deveriam ser superados e consignar aquelas instituições e diretrizes que deverão ser conquistadas, apropriadas e defendidas. Não ter clareza dessas contradições pode comprometer sobremaneira as gerações futuras. Vamos começar por um exemplo real e histórico: a questão da situação dramática da juventude brasileira, aqueles que são, em última instancia, a grande maioria de nossos alunos, ainda que sob outras marcas ou origens de classes.

A população considerada jovem no Brasil, aquela que se situa na faixa etária de 15 a 29 anos beira hoje a $21 \%$ da população brasileira total, ou seja, expressa um conjunto de mais de quase 40 milhões de pessoas. Mesmo que se reduzisse unicamente a uma consideração de natureza demográfica e quantitativa o destaque e o protagonismo 
histórico dessa faixa etária já haveria de justificar, da parte da sociedade e do Estado, a proposição de um razoável número de serviços, disposições, planejamento, manejo e atuação, para dar conta das necessidades de toda sorte dessa proeminente multidão de cidadãos e cidadãs que se encontrariam numa etapa potencialmente considerada como das mais criadoras e originais da existência humana.

Todavia, se propusermos critérios de natureza histórica, com ampliações derivadas da investigação política, nossas constatações ampliariam essa primeira importância reconhecida, de estrita base quantitativa e reduzida análise populacional: qual seria o contingente de jovens que trabalham, quais seriam as bases salariais desse contingente, quais seriam os indicadores de acesso e permanência das maiorias jovens na escola, quais seriam os níveis de escolaridade da população jovem, qual seria a cobertura pública de vagas e ofertas de ensino, quais seriam os indicadores de oferta de trabalho, planejamento ocupacional e produção de postos de trabalho para essa "onda jovem" que não pára de crescer em nossa sociedade; ainda mais, quais seriam os produtos e disposições de uma política de lazer voltada para essa faixa etária? Seriam tantas as perguntas e talvez pudessem ser muito trágicas as possíveis respostas.

Se considerarmos ainda que grande parte de nossa população jovem vive abaixo das linhas sócio-econômicas que expressam indicadores de qualidade de vida, são jovens que trabalham e são remunerados em condições exploratórias, quando não formam exércitos de desocupados, desempregados, sub-empregados, informais, volantes, sem expectativas de inserção produtiva e planejada no mundo do trabalho estrutural a premissa começa a parecer ainda mais com os anúncios de uma tragédia social. Metade da população jovem brasileira não tem renda própria.

E se qualificarmos um pouco mais nosso olhar, por exemplo, aproximando nossos sujeitos dos dados sobre educação em nosso país. Como vimos acontecer a educação dos 
jovens no Brasil? Outros interditos nos assaltam, outras tragédias se elaboram. A análise da ocupação e demanda do sistema escolar oferece ainda outra dramática silhueta, a grande maioria dos jovens não termina o ensino médio e somente $12 \%$ encontra-se em condições de freqüentar o ensino superior, ainda que considerando a expansão quantitativa de vagas operadas nas última décadas, mesmo que tenhamos que reconhecer a desproporcional ascensão das vagas de caráter privado.

Assim, herdeiros de graves problemas sociais históricos, tributários da pobreza de seus universos familiares, candidatos à baixa qualificação educacional e escolar, à baixa remuneração e às poucas oportunidades de trabalho, premidos pelos desníveis sociais cada vez mais estratificados, pressionados por uma sociedade consumista e pansexualista marcada pela exposição de tudo como mercadoria, dilacerados pela crise institucional da unidade parental básica, ou família, expectadores das carências e lacunas dos serviços sociais mais fundamentais a juventude se vê aturdida entre os apelos de uma sociedade hedonista, os ditames de uma acentuada marginalização social e o espectro do pior de todos os sintomas dessa desestruturação orgânica: a violência como cultura e produção de morbidade juvenil.

Os índices anuais de mortalidade no Brasil, considerando a população em sua totalidade, definem 67 óbitos para um contingente de 100 mil pessoas. Todavia, se consideramos a faixa etária de 15 a 29 anos, esse índice se altera para 106 mortes anuais para um contingente de 100 mil pessoas. Desse universo, somente $12 \%$ referem-se à mortalidade feminina, os demais e macabros números de $88 \%$ referem-se à população masculina. Um esforço para caracterizar ainda mais esse dantesco quadro não seria tão difícil: jovens pobres, nascidos na periferia, expostos a toda sorte de riscos sociais, sem os cuidados básicos de assistência na educação, saúde, trabalho, moradia e lazer, envoltos em bárbaros cinturões que articulam miséria e criminalidade, são os sujeitos 
estatísticos que marcam as páginas do necrotério da história social atual. Tais índices de nosso triste país somente são comparáveis a universos de marginalização como da Colômbia, nucleada nas zonas de disputa do narcotráfico internacional, ou de sociedades em processos de históricas lutas e guerras civis.

Quais seriam, portanto, as definições políticas que essas poucas e dramáticas cifras poderiam nos inspirar? A primeira constatação é a enorme dívida social que o Estado e mesmo a sociedade civil, tem para com a juventude brasileira. Somente uma esclarecida determinação política pode considerar tais indicadores e propor, com coragem e tenacidade, um conjunto de políticas públicas voltadas prioritariamente para a juventude. Tais disposições devem nascer da consciência ética da responsabilidade do Estado sobre esses segmentos e da premissa política e emancipatória da potencialidade criativa e educacional dessas populações etárias. A escola e a educação são as formas e forças sociais de maior inserção e intensidade na vida dessas gerações. Sobretudo, tratase de construir uma nova cultura pedagógica, curricular e administrativa, a estimular a escola e a educação a produzir emancipação, igualdade e cidadania, as únicas semente embrionárias da justiça e da paz.

Para nós a educação é a produção social e emancipatória do homem. Significa compreender que a construção do homem, livre, produtivo, esclarecido, consciente, sensível e solidário, aberto aos processos sociais e comunitários, é um processo permanentemente aberto e desafiador. Nessa direção a Escola é a instituição histórica socialmente responsável pela transmissão formal do conhecimento socialmente acumulado. A Escola que desejamos construir, entendida como uma comunidade de investigação, embasada nos princípios e valores da democracia e da cultura da paz, nascerá de suas próprias marcas institucionais. Entendemos por currículo a articulação dos conteúdos de ensino, das relações sociais e institucionais da Escola, com a cultura da 
cidade e do bairro, com os ideais nacionais e as marcas regionais, a grata união das vivências e saberes, das descobertas teóricas e originalidades práticas, configurando em cada unidade educacional o seu genuíno projeto político pedagógico a partir das diretrizes administrativas que envolvam a comunidade escolar, em esferas diferenciadas de integração.

Reconhecemos que somos herdeiros de uma concepção de Educação, consolidada na sociedade atual, que estabelece o homem como um mero produto a ser preparado para o mercado de trabalho, em detrimento de sua formação humana, ética, política e estética. Proliferam-se discursos que caracterizam a educação como capital de competências para o trabalho alienado, ou como a mera habilitação para um desenvolvimento estéril ou ainda a conquista de uma tecnologia sem alma ou identidade. Descura-se da educação para a paz e para sensibilidade, para a formação voltada para assumir suas responsabilidades sociais. Predomina a compreensão utilitarista da educação como uma habilitação ocupacional para a inserção no mundo do trabalho, perpassada por uma ideologia da mobilidade social, do subir socialmente a qualquer preço, cultivada pela exacerbação da competição, caracterizada por um individualismo consumista em todas as suas formas.

Identificamos haver hoje uma contraditória relação institucional entre a Escola e a Família. As mudanças recentes da sociedade brasileira impuseram profundas transformações na família brasileira, quer pela alteração do papel social da mulher, quer pelo advento da sociedade de massas, trazendo juntas a acelerada expansão das cidades e o desenfreado apelo ao consumo. Neste processo, em muitas situações, a família terceirizou à Escola, com o consentimento tácito da mesma, muitos dos fundamentos da educação geral que eram atribuições inalienáveis da família. Decorre disto, entre outras contradições, um conflito no estabelecimento de responsabilidades e limites no processo 
de formação da criança, do adolescente e da própria juventude. Na maioria das vezes a participação dos pais no processo escolar reveste-se de uma forma clientelista, assistencialista, muitas vezes patrulhadora ou marcadamente ausente. Cabe à Escola pública emancipatória, que sonhamos constituir como nosso horizonte utópico, repensar esta relação e buscar circunscrever os limites e pertinências de sua identidade institucional.

Decorrente desta contradição as escolas não conseguem motivar a grande maioria dos alunos para o aprendizado formal, muito menos para uma visão emancipatória e crítica. Aqui e ali surgem manifestações de pessimismo, de notável abandono, quando não se vive um ambiente de tédio e desmotivação na comunidade escolar. A sociedade de consumo provoca uma abundância de estímulos materiais e tecnológicos que concorrem com a aquisição reflexiva e humanizadora do conhecimento na Escola.

O professor tem sofrido um duro processo de expropriação de seu conhecimento e saber, de prestígio social e reconhecimento profissional, além da negação ou repressão no campo econômico. Premido por jornadas superpostas de trabalho e submetido a um acelerado processo de perda de prestígio social o professor tem visto a escola como um local do exercício profissional mais restrito e não da produção da educação e formação do homem para a vida em sua totalidade. Nós reafirmamos a necessidade de construir e formar o professor permanente e continuamente para exercer seu papel fundamental na emancipação da sociedade.

Entendemos o homem como o princípio e o fim da educação, política, ética e cultural, o ser e sujeito onde estão presentes dualidades que não se separam. A Escola pública, leiga, universal, gratuita, estatal e obrigatória, herdeira da tradição democrática, terá que levar em consideração essa dualidade, compreendendo que essa característica estará presente na formação integral, assumindo que a relação do Homem com o Mundo 
é de interdependência e dualidade. A educação da criança é a esperança do mundo, da sociedade, da cidade e do grupo social onde nos situamos. Compreendemos a educação como aquisição de conhecimentos, hábitos e vivências, como forma idiossincrática de apropriação da cultura e formação para a inserção produtiva na sociedade. É espaço de tomada de consciência da condição humana e lugar do erigir a gênese do debate ético cujo resultado implicará diretamente na forma como a sociedade se organizará, devendo estar inserida no centro do projeto de toda sociedade, não espelhando uma sociedade ficcional. Educaremos para a participação consciente na construção social, para que cada educando possa saber assumir responsabilidades perante a inalienável tarefa de permanente formação dessa mesma sociedade. Essa educação necessita que todos os cidadãos apóiem as ações e reforcem as tendências sociais para formação de sujeitos que tenham preparação escolar para integrar o trabalho, mas como mediação para a vida em coletividade, como dimensão política e condição existencial como interventores esclarecidos e não como sujeitos passivos. Esta premissa exige das escolas um olhar constante para essas tendências como forma de garantir seu compromisso com a formação do cidadão comprometido com seu processo social e histórico.

Nesse cenário é que situamos a ação orgânica dos educadores sociais, tal como identificamos os profissionais da educação, da saúde publica, quer ainda os profissionais do serviço social: como sujeitos institucionais e políticos que tem como função e ofício garantir o cumprimento da função social da escola e manejar para a transformação das condições objetivas de trabalho na instituição educacional, hospitalar, ou quais quer outras. Ao intentar superar a tradição autoritária e a inspiração tecnicista de sua identidade tradicional o agente de saúde, o educador, o profissional de serviço social se vê convocado a construir as bases da nova educação, a cidadania emancipatória: construtiva, participativa, criadora, democrática e integradora. Como intelectual orgânico 
esse sujeito de novas práticas sociais poderá produzir reflexões, representações e significados novos aos níveis e graus de toda prática social. Seu trabalho envolve a dimensão pedagógica por excelência, com a sensibilidade para articular suas especificidades com o ideal de humanização em curso na sociedade em geral. Sua inspiração poderá ser a nova sociedade civil brasileira, uma realidade igualmente inusitada, que delineia seus contornos institucionais na trilha da conjuntura atual das últimas décadas. Nesse universo o sujeito profissional emancipatório é encarregado pela história de definir seus interlocutores preferenciais: a criança, o adolescente, o portador de necessidades especiais, a mulher, o negro e o índio, o meio-ambiente, as minorias sexuais, o idoso, entre algumas vanguardas grávidas de direitos que vislumbramos em nossa realidade. Com tais sujeitos se cristalizam as práticas e condições reais de emancipação, através da ressignificação da prática social da educação e da saúde públicas e das finalidades próprias da educação escolar, da ação hospitalar e atendimento aos grupos sociais marginalizados ou excluídos.

Qualquer observador atento haverá de perceber a pluralidade de discursos messiânicos sobre a função social da educação, sobretudo nessa estéril conjuntura chamada de crise, e os múltiplos posicionamentos políticos que se arvoram diante do tema. Entre as variadas prescrições para uma suposta superação de nossa tradição excludente encontra-se a anunciação da questão da interdisciplinaridade. O que podemos entender desse conceito e sua potencialidade política? A resposta a essa questão tem que ser dada rente aos fatos sociais, aos movimentos e universos políticos que a condensam de sentido.

No tocante à avaliação das matrizes de nossa organização educacional e escolar não é de todo uma atitude passadista voltar aos consistentes estudos de Nagle (1984), sobre as matrizes políticas e pedagógicas de nossa tradição educacional republicana: a 
pendular dialética entre o entusiasmo pela educação e o otimismo pedagógico. Cumpre lembrar que o teorema de Nagle só se resolve com um outro princípio: a determinação política, que se torna matricial para o esclarecimento das demais disposições. Assim, para a compreensão da potencialidade política e fecundidade epistemológica e didática da proposição de uma ação multiprofissional ou interdisciplinar não se trata aqui de uma mera consideração demiúrgica, de base idealista, dessa palavra ou propósito pedagógico, trata-se da decifração de sua natureza política e radicalidade histórica. A questão que nos move nos permite perguntar se esse ideal pedagógico-educacional, aparentemente uma unanimidade nacional, seria forte o suficiente para superar a arraigada e eficiente tradição político-pedagógica e teórico-metodológica autoritária que engendra o núcleo de nossa formação política e cultural?

Um primeiro questionamento nos remete às matrizes de nossa organização política. O Estado, classicamente, precede a sociedade. Entre nós a pauta foi quebrada. O arcaico estado português mercantilista constituiu aqui uma feitoria de exploração, pautada na crueldade extrativista e administrativa, abençoada pelas necessidades salvacionistas de uma Igreja tridentina acuada pelo avanço das teses modernas e da configuração religiosa reformista. La yspada y la cruz iban dizimando la família selvajecantava Neruda, ecoando ainda hoje nessas selvas, campos e montanhas, chacos e pantanais. Fomos constituídos às avessas da modernidade, distantes de suas grandes linhas, jurados apologetas do arcaico e legionários combatentes da modernidade, da colônia ao império.

E a industrialização do Brasil, como se dá, a partir do conúbio entre o campo e a cidade, parida a fórceps por um estado beirando ao totalitarismo, sustentado sobre o crescimento econômico desvinculado de responsabilidades sociais distributivas. Hoje celebramos quase oitenta anos de um modelo de desenvolvimento capitalista, que nos 
coloca em duas posições distintas: o $11^{\circ}$ PIB do mundo e o $69^{\circ}$ IDH do planeta, na mesma escala decimal de Namíbia e Suazilândia. O Estado Novo, a república populista e a inolvidável ditadura militar completaram o quadro econômico e suas conseqüentes margens sociais.

Num terceiro tempo de nossa sumaríssima reconstrução de marcos políticos, temos que tomar a distância correta para entender como se tem manejado o processo de integração da economia brasileira ao mundo globalizado, dos capitais internacionalizados, efetivado a partir de 1990. A nossa subserviente integração à era dos capitais, ao tempo da desempregabilidade estrutural, do anunciado manejo das potentes tecnologias e da construção de novas estratégias de poder, da ampla massificação do consumo e da virtualização do conhecimento e da cultura tem se dado de maneira avassaladora.

Mas é forçoso perguntar: a que tradição da modernidade nos filiamos, a que linhas éticas, estéticas e políticas do renascimento artístico, do esclarecimento filosófico e da fecundidade do iluminismo científico nos vinculamos, conforme prescrições da sociedade burguesa liberal? A nenhuma! Entre nós tem vencido a reação, o atraso, o conchavo, a cooptação, as contra-revoluções. Seria possível superar uma tradição moderna disciplinar, especializada, por uma proposta de reestruturação política e curricular, de natureza interdisciplinar, ou ainda a ação profissional sobre especialidades para a abertura da pluralidade multiprofissional, sem considerar as matrizes da relação da educação, da universidade e da escola com o mundo social, natural e cultural, para além dessas coordenadas? Ou seria necessário instituir esse abissal questionamento: para nós seria fundamental a disposição de buscar conhecer o que fizeram de nós, para escolher o que poderemos fazer com o que fizeram de nós, para relembrar a elementar crítica da razão dialética de Sartre. 
A disciplinarização e a interdisciplinaridade não são meros princípios de organização escolar, de administração hospitalar, de representação institucional, pressuposta em dispositivos administrativos e curriculares. São princípios políticos. Demandam o reconhecimento do mundo, da ação do homem na natureza e sociedade, da função social e política da escola, da universidade, do estado, da cultura, de tudo o que existe, enfim. Os ordenamentos curriculares e a organização institucional da escola e da universidade resultam de seleções políticas, arbitrárias, constituídas a partir de interesses definidos, envoltos em relações de poder e expressos a partir de determinados objetivos sociais. Trata-se de buscar um outro modo de olhar o mundo, a ciência e a política, capaz de constituir novas estruturas de convivência, trabalho e produção de saberes.

Basta olhar para a herança do século XX, a constituir ainda as bases de nossos tateantes passos, que terminou com a exposição de enormes contradições e paradoxos sociais: o grande aumento da produção de bens e serviços e a prevalência da desigualdade entre os povos ou o "alargamento do abismo entre os países ricos e pobres do mundo"; o fosso entre alfabetizados e analfabetos (especialmente funcionais); por um lado, o avanço da revolução tecnológica, especialmente nos transportes e nas comunicações e, por outro lado, inquietações, incertezas, desconfiança no futuro, gerados pelos barbarismos, hostilidades diversas, guerras sem razão que tiveram como grande vítima as populações civis, catástrofes humanas que produziram, desde as maiores carências e mortandades pela fome, registradas na história, até o genocídio sistemático. Vimos hoje o descalabro do aquecimento global, a proliferação de pandemias e, junto a isso, a ausência de esperanças reais!

Temos clareza que as concepções organizacionais de pesquisa e ação educacional sustentadas por uma concepção dogmática de ciência e saber, calcadas na desgastada concepção positivista e evolucionista da História, a identificar a marcha do capital como 
a realização plena da história, enquadrada em etapas contínuas e deterministas; todas essas concepções não servem à causa da emancipação. Teremos que, por força de uma tradição educacional, institucional e escolar ex privilegio, excludente e seletiva, produtora ou reforço da marginalização social, superar a concepção de organização da pesquisa, da docência e ação social baseada em disciplinas estanques, datações rígidas, movimentos descritivos e causas justificadoras de todas as formas de hegemonia políticas das elites proprietárias em nosso país. Mas, reorientar a interpretação da organização política e pedagógica da produção do conhecimento, da formação de professores, da ação institucional dos trabalhadores sociais e da saúde não significa abandonar suas bases racionais e reduzi-la a um conjunto de fragmentos, impressões e simulacros descontínuos. Temos clareza que as concepções de interdisciplinaridade e transversalidade, de inspiração francesa, nascidas das diversas gerações da tradição política crítica, contêm um fulcro rigoroso de embate com a concepção moderna, o que precisaria ser muito mais contextualizado e aprofundado, antes de se traduzir numa fundamentação filosófica espúria.

Por razões de ofício, nas Ciências Humanas e Sociais, somos convocados a definir as disposições basilares de nossa vida e existências coletivas. Não é sem razão que Bauman afirma que a globalização acentua-se sobre duas negações, o fim da história preconizado por Fukuyama e a disposição de decretar o fim da geografia, denunciada por Paul Virilio. O tempo pós-moderno, entendido como expressão da globalização, é um tempo presentista, de fruição incessante, sem passado, sem conexões que possam ser ressignificadas dialeticamente; um tempo sem a marca da seta de Prigogine a nos indicar a única possibilidade de esperanças, o futuro. Os planejadores do escrutínio do tempo do capital globalizado parecem desejar o delírio do imutável, a cessação do dinamismo, e a decretar a cíclica retenção ou repetição do mesmo, num delírio solipsista voraz. O espaço 
pós-moderno é a miragem da extraterritorialidade, do descontínuo, do simulacro, a visão da fantasmagoria, essa matrix política encarcerada no gozo da posse da mercadoria, na ânsia de consumir para ser, para existir. Um quadro de Goya pode muito bem esclarecer nossa contradição, o duelo de porretes sobre a areia movediça.

Assim, se o tempo e espaço modernos abriam possibilidades para a ação consciente de homem, para a delimitação do espaço material, do novo significado do corpo, das dimensões do espaço público e privado, a desterritorialização devassa nossas fronteiras topográficas, derruba nossas marcas ontológicas e nos submete à ditadura da opacidade e da descontinuidade, da desrazão e das sombras. Nossa proposta consiste em olhar para trás, encontrar numa coerente visão do tempo e delimitação generosa e democrática dos espaços reestruturando nossa possibilidade de reorientação da modernidade, superando a razão instrumental por uma refundação da razão dialógica e da prática emancipatória, a enunciar nossos sonhos, nossa capacidade utópica de ir para a frente.

A adoção desse princípio político deverá ser capaz de superar a concepção fragmentária que confunde interdisciplinaridade com pluri-especialização ou estratos e contigüidades dispostas artificialmente, com o risco do sincretismo e da superficialidade. Compreender a realidade a partir da categoria da totalidade, numa abordagem de radicalidade e de conjunto parece ser a premissa de um pensamento e de uma ação profissional inclusiva, humanizadora e interdisciplinar. Mesma atitude deveria ser vista em relação ao princípio da contextualização de cada conhecimento, saberes e ciências, e essa disposição não deveria ser entendida como uma proposta de esvaziamento, como uma proposta redutora do processo ensino-aprendizagem, da relação sujeito-paciente circunscrevendo-o ao que está no redor imediato do sujeito aprendente ou doente, restrita a suas experiências subjetivas e vivências singulares. 
Nossa disposição aponta para a necessidade de uma nova tradição política a conformar uma nova definição do papel do conhecimento, do Estado e dos saberes, na sociedade brasileira. Vimos nascer uma vigorosa marcha da sociedade civil brasileira, nos últimos decênios, a produzir uma diversidade de temas e sujeitos históricos emancipatórios em busca da superação de estigmas culturais fossilizados. Neles reside a novidade, especialmente voltada para os ofícios das Ciências Sociais, que haveriam de criar instrumentos de produção de esclarecimentos para além da contabilidade do sofrimento, com particular atenção ao sofrimento socialmente produzido, e daí também, ser capaz de ser historicamente superado. Quando a emancipação e o processo de humanização for assumido como princípio político certamente engendrará dispositivos epistemológicos e eixos articuladores da pesquisa, do ensino e da organização das instituições educacionais, das instituições de saúde e de formação humanizadora, da escola básica à universidade.

\section{ABSTRACT}

This article intends to characterize the political and cultural sources of our social practice, focusing the identities produced by the colonial tradition, superimposed by brazilian empire political experience, both scheduled from the hegemony of slavocrat and patriarcal relationships, consecrated by the omnipotence of the State and his influence on political reality. The Republic and its phasis or stages does not change this identity up to the appearance of a new social subject, recognized in the conflicts and in social movements which have conquered the country redemocratization after the militar dictatorship (1964-1985), assigning a new historical, judicial and social landmark, materialized in the new grades of laws and social rights: the Estatuto da Criança e do Adolescente (the Child and Adolescent Statute), the SUS (United Health System), the institutions for protection and women's right, the efforts for ethnical and cultural equality, the public politics for inclusion and social repairing initiatives, the perspectives of a new Brazil environmental "ethos", the social custody recognition of the aged people, of individuals with special needs, of indians, of negroes, of 
homosexuals, among others segments and civil emancipationist vanguard. It presents the historical tendencies and the ethnical and political representatives of this domination tradition and shows the possibilities for reversing, surpassing and disarticulating these tendencies or authoritarian matrix from the political practice, the resignification of the ethical and educational background, the reconstitution of social values in a prospectus of solidarity, humanization, social justice and political democratization

KEYWORD: Humanization, Education, Emancipation, Ethical, Social Work.

\section{REFERÊNCIAS BIBLIOGRÁFICAS}

BAUMAN, Z. Globalização: as conseqüências humanas. Rio de Janeiro: Jorge Zahar Editor, 1999.

HABERMAS, J. O discurso filosófico da modernidade. São Paulo: Martins Fontes, 2001.

VIRILIO, P. The Lost Dimension. New York: Semiotext, 1991.

HOBSBAWN, E. A Era dos Extremos: o breve século XX. Rio de Janeiro: Paz e Terra, 1998.

PRIGOGINE, I. A administração do caos. São Paulo: Companhia das Letras, 2004.

SARTRE, J. Crítica da Razão Dialética. São Paulo: Paz e Terra, 1989.

ANDERSON, P. O Fim da História: de Hegel a Fukuyama. Rio de Janeiro: Jorge Zahar Editor, 1992.

NUNES, C. Educar para a Emancipação. Florianópolis: Editora Sóphos, 2003.

Campinas, Outono de 2009. 